\title{
INVESTIGACIÓN
}

Recibido: 10/01/2021 --- Aceptado: 25/03/2021 --- Publicado: 10/05/2021

\section{EXPRESIÓN Y EXPERIENCIA EMOCIONAL DE LA PANDEMIA COVID-19 MEDIANTE LA MEMÉTICA EN UN PERFIL DE FACEBOOK DE UNIVERSITARIOS MEXICANOS}

\author{
Expression and emotional experience of the covid-19 pandemic through \\ memetics in a facebook profile of mexican college students
}

\author{
(iD) $\mathbb{R}^{a}$ Gabriela Rodríguez-Hernández ${ }^{1}$ : Universidad Autónoma del Estado de \\ México. México. \\ grodriguezh@uaemex.mx
}

Karla Patricia Cruz Calderón: Universidad Autónoma del Estado de México. México.

kpcruzc@uaemex.mx

Mariana Ramírez Hernández: Universidad Autónoma del Estado de México. México. mramirezh@uaemex.mx

\section{Cómo citar el artículo:}

Rodríguez-Hernández, G., Cruz Calderón, K. P., Ramírez Hernández, M. (2021). Expresión y experiencia emocional de la pandemia covid-19 mediante la memética en un perfil de Facebook de universitarios mexicanos. Vivat Academia. Revista de Comunicación, 154, 89-106. http:// doi.org/10.15178/va.2021.154.e1297

http://www.vivatacademia.net/index.php/vivat/article/view/1297

\section{RESUMEN}

El objetivo de este trabajo es explorar la expresión y experiencia emocional de la pandemia COVID- 19, a través de un perfil de Facebook de universitarios mexicanos. En este estudio de caso se utilizó el método etnográfico virtual con la intensión de realizar un estudio detallado y avanzar en el conocimiento teórico del fenómeno en cuestión. La recuperación y análisis de la información se efectuó durante los meses de marzo a julio de 2020. Se capturaron un total de 113 memes de los cuales 55 (48.7\%) expresaban emociones vinculadas con la pandemia. De los resultados se advierte que el meme es un sistema complejo en el que intervienen procesos cognitivos y juegos de lenguaje propios de la cultura donde se usan, favoreciendo la expresividad y las formas de compartir y ser afectuoso durante la pandemia. Prevalece la expresión de emociones negativas como el pesimismo, la desesperación, el miedo y la soledad; 
Rodríguez-Hernández, G., Cruz Calderón, K. P., Ramírez Hernández, M. Expresión y experiencia emocional de la pandemia covid-19 mediante la memética en un perfil de Facebook de universitarios mexicanos

también se expresan emociones positivas como el asombro, el optimismo y la serenidad. Los resultados encaminan a comprobar parcialmente el supuesto de investigación en el entendido que las emociones que predominaron, si bien, son negativas, no son las emociones que se han identificado como parte de las premisas histórico-socio-culturales de la expresión emocional en los mexicanos. Se discute sobre la función edificadora de los memes para delinear pautas expresivas de valoración y planificación de la nueva realidad al constituirse en referentes que operan como unidades culturales que articularon actos comunicativos para proveer de sentido e identidad a los usuarios.

PALABRAS CLAVE: internet - meme - emociones - nativos digitales - cultura comunicación - expresión

\section{ABSTRACT}

The aim of this paper is to explore the expression and emotional experience of the COVID-19 pandemic through a Facebook profile of Mexican university students. In this case study, the virtual ethnographic method was used with the intention of carrying out a detailed study and advancing theoretical knowledge of the phenomenon in question. The recovery and analysis of the information was carried out during the months of March to July 2020. A total of 113 memes were captured, of which $55(48.7 \%)$ expressed emotions linked to the pandemic. The results show that the meme is a complex system involving cognitive processes and language games specific to the culture in which they are used, promoting expressiveness and ways of sharing and being affectionate during the pandemic. The expression of negative emotions such as pessimism, despair, fear and loneliness prevails; positive emotions such as astonishment, optimism and serenity are also expressed. The results lead to a partial verification of the research assumption in the understanding that the predominant emotions, although negative, are not the emotions that have been identified as part of the historical-socio-cultural premises of emotional expression in Mexicans. We discuss the edifying function of memes in delineating expressive patterns of valuation and planning of the new reality by constituting referents that operate as cultural units that articulate communicative acts to provide meaning and identity to users.

KEYWORDS: internet - meme - emotions - digital natives - culture - communication - expression

\section{EXPRESSÃO E EXPERIÊNCIA EMOCIONAL DA PANDEMIA COVID-19 ATRAVÉS DA MEMÉTICA EM UM PERFIL DE FACEBOOK DE UNIVERSITÁRIOS MEXICANOS.}

\section{RESUMO}


Rodríguez-Hernández, G., Cruz Calderón, K. P., Ramírez Hernández, M. Expresión y experiencia emocional de la pandemia covid-19 mediante la memética en un perfil de Facebook de universitarios mexicanos

O objetivo deste trabalho é investigar a expressão e experiência emocional da pandemia COVID-19, através de um perfil de Facebook de universitários mexicanos. Neste estudo de caso se utilizou o método etnográfico virtual com a intenção de realizar um estudo detalhado e avançar no conhecimento teórico do fenômeno em questão. A recuperação e análise da informação foi feita durante os meses de março a julho de 2020. Foram coletados um total de 113 memes dos quais 55(48,7\%) expressavam emoções vinculadas com a pandemia. Dos resultados se obteve que o meme é um sistema complexo onde intervêm processos cognitivos e de linguagem próprios da cultura onde são usados, favorecendo a expressividade e as formas de compartilhar e da afetividade durante a pandemia. Prevalece a expressão de emoções negativas como o pessimismo, o desespero, o medo e a solidão, também se expressam emoções positivas como o assombro, o otimismo e a serenidade. Os resultados se encaminham a comprovar parcialmente o objetivo da pesquisa onde se supõe que as emoções que predominaram, se bem, são negativas, não são as emoções que são identificadas como parte da premissa histórico-sócio-cultural, da expressão emocional dos mexicanos. Se discute sobre a função edificadora dos memes para dar pautas expressivas de valoração e de planejamento da nova realidade ao constituir se como referências que operam como unidades culturais que articularam atos comunicativos, para dar sentido e identidade aos usuários.

PALAVRAS CHAVE: Internet - meme - emoções - nativos digitais - cultura comunicação - expressão.

\section{INTRODUCCIÓN}

La memética presupone que todo lo que sucede en los distintos ámbitos de la vida del ser humano, llámense política, arte, ciencia, economía, salud, etc., es una imitación selectiva que se propaga de cerebro a cerebro a partir de un elemento original. La imitación - que no es una copia exacta - se replica hasta llegar a ser una transmisión cultural (Dawkins, 1993). La unidad de imitación es lo que se define como meme, el cual transmite la información de forma cultural, longitudinal y horizontalmente (Arango, 2015; Pérez et al., 2014). El elemento original imitado tiene un carácter multisemiótico, pues puede ser una frase o secuencia de frases, una imagen, un video, un gif o una combinación de todos estos (Pérez, 2017; Ruiz 2018). La forma multisemiótica es la que hace al meme un sistema complejo en el que intervienen procesos cognitivos como la selección, la imitación, el aprendizaje y la asimilación; además de juegos de lenguaje en una dimensión cultural específica que provoca que algunos comportamientos sean imitados y otros no. Un meme es un grupo de elementos digitales compartidos con conciencia mutua que circulan, imitan o transforman a través de internet (Milner, 2016).

El meme es un fenómeno que ocurre al interior de grupos y comunidades que establecen su sentido a partir de la interacción (Pérez, 2017). Los memes cumplen su función cuando son reconocidos por los participantes en el acto comunicativo 
Rodríguez-Hernández, G., Cruz Calderón, K. P., Ramírez Hernández, M. Expresión y experiencia emocional de la pandemia covid-19 mediante la memética en un perfil de Facebook de universitarios mexicanos

alterando su comportamiento y motivación para difundir el patrón (Pérez et al., 2014). Como patrón de información puede ser usado incluso como recurso educativo; hasta la política ha entendido este fenómeno y lo ha utilizad como un medio de transmisión de mensajes propagandísticos efectivos y poderosos hacia los nativos de la web (Vera, 2016). También se utilizan para conformar y reflejar estados de opinión (Ruiz, 2018) y estados de ánimo (Ballesteros, 2016). Los memes, en su vertiente humorística, son breves estímulos cómicos que pretenden provocar la risa o, al menos, una sonrisa (Urroz, 2005).

La forma en que el meme se replica, plantea reflexiones sobre la puesta en práctica de procesos comunicativos en los cuales adquiere un uso socialmente construido, así como sentido, el cual es compartido por aquellos que lo incorporan dentro de sus bagajes simbólicos (Almeida, 2019; Pérez et al., 2014). Los memes en el mundo virtual reflejan la cosmovisión de la cultura popular, y por la rapidez con que se difunden tienen un carácter efímero, aunque tienden a ser democráticos, porque pueden ser creados por cualquier usuario de internet con una aplicación o cualquier editor de imágenes, y acceso a una red para compartir (Ruiz, 2018).

Crear y compartir memes a través de la red social Facebook se ha convertido en una práctica en la que los jóvenes (nativos digitales) participan de manera cotidiana. Son memes a través de los cuales expresan sus vivencias del día a día en los distintos contextos de práctica en los que participan y con las diferentes personas con quienes se relacionan. Ante la ocurrencia de eventos significativos realizan la búsqueda o la elaboración de los memes que ejemplifiquen la vivencia que quieren mostrar, lo cual resulta habitual, pues los nativos digitales, no conocieron el mundo sin la tecnología o la integraron a su vida desde edad temprana. Asimismo, permanecen conectados todo el tiempo y prefieren la comunicación gráfica por encima de la textual por la inmediatez que está implica; también han construido sus propios conceptos de espacio, tiempo, número, causalidad, identidad y memoria a partir de los objetos digitales que les rodea (Gallardo, 2012; Izquierdo y Barbeta, 2013).

\subsection{Experiencia y expresión emocional}

Actualmente, el meme representa una de las formas de comunicación más utilizadas para expresar y experimentar emociones - lo que para algunas personas resulta abrumador tratar abiertamente - , al mitigar la aflicción de hablar de aspectos íntimos o personales; además de ser un vínculo con la realidad que permite a los usuarios caer en la cuenta que lo que le pasa a uno les ocurre a muchos otros.

En este punto, la pandemia de COVID-19 declarada por la Organización Mundial de la Salud el 11 de marzo de 2020 ha implicado un reto de Salud Pública de envergadura extraordinaria, toda vez que su impacto alcanza a casi todos los países del mundo. En México se cuentan ya decenas de miles de fallecidos y una potencial crisis en materia de salud, economía, soberanía alimentaria y seguridad (Observatorio Nacional Ciudadano, 2019). La pandemia provoco meses de confinamiento, situaciones críticas en hospitales, duelos sin despedidas que podrían dar paso a una 
Rodríguez-Hernández, G., Cruz Calderón, K. P., Ramírez Hernández, M. Expresión y experiencia emocional de la pandemia covid-19 mediante la memética en un perfil de Facebook de universitarios mexicanos

crisis de salud mental, considerando que el impacto emocional puede agravarse. Los memes de internet como una pieza cultural, típicamente una broma, ganan en importancia con la pretensión de relativizar y poner distancia desde el humor, a las tensiones, malestares y conflictos de la vida cotidiana (Vigara, 2013).

Las emociones están presentes en cualquier momento de la vida y se experimentan con suficiente intensidad para tomar conciencia de estas, identificar su causa y el efecto, así como el sentimiento agradable o desagradable que provocan y la súbita alteración del organismo, contenido en los cambios del comportamiento (Hansberg, 2001). Las emociones han sido consideradas total o parcialmente como cogniciones o como factores dependientes de la lógica de estas. Se ha propuesto la existencia de una conexión lógica entre las emociones y las creencias evaluativas, pues lo que se siente sobre la demás gente, los sucesos y las cosas, es producto del valor otorgado por la sociedad o el grupo social de pertenencia. Incluso se ha señalado la existencia de pautas universales para la expresión de emociones básicas como la ira, el enojo, la alegría, el disgusto, la ansiedad y la tristeza (Ekman et al., 1982; Plutchnick, 1980).

De igual forma, las emociones son configuraciones socioculturales que permiten explicar lo social mediante polifonías narrativas que acontecen en el flujo de la vida cotidiana (Enríquez-Rosas, 2016). Se objetivan a través de un vocabulario emocional en correspondencia a matrices socioculturales y se manifiestan en rituales que atienden fronteras simbólicas más o menos explícitas y conscientes para su regulación (Gordon, 1990). Las emociones pueden variar en función de las costumbres, normas y creencias sociales, por lo tanto, variara la forma de reaccionar y de entender una emoción o sentimiento dependiendo la cultura de que se trate (Mercadillo et al., 2007). Pensar las emociones como construcciones sociales, deriva de la interpretación que hacen las personas de su propia conducta emocional, de las aferencias - estímulos que van desde los receptores sensoriales hasta el Sistema Nervioso Central - que conducen a la activación fisiológica y a la expresión manifiesta (Rodríguez-Hernández et al., 2017).

La expresión de las emociones se torna en un elemento indispensable para su definición y representación, al facilitar la discriminación de los estados emocionales, los cuales juegan un papel central en la interacción social. El proceso de experiencia y expresión de la emoción se desencadena por la percepción de condiciones internas y externas que dan lugar a la evaluación valorativa, experiencia que produce expresión corporal, lenguaje verbal y no verbal que se transfigura en un fenómeno observable (Lyubomirsky et al., 2005). La conexión entre una emoción y su expresión no sólo es una cuestión de causa y efecto, la conducta de una persona está en el contexto en donde se expresan las emociones, así como en la acción o el gesto. Algunas veces, la conexión entre la emoción y su expresión es clara, mientras en otras, la relación se complica en la medida en que la identificación de la propia emoción no resulta tan evidente (Calhoun y Solomon, 1996; Garrido, 2000; Hansberg, 2001; Aguado, 2005).

\subsection{Cultura emocional mexicana}


Rodríguez-Hernández, G., Cruz Calderón, K. P., Ramírez Hernández, M. Expresión y experiencia emocional de la pandemia covid-19 mediante la memética en un perfil de Facebook de universitarios mexicanos

La cultura afecta en cómo se experimentan las emociones, pues las dota de valoraciones positivas o negativas en el sentido de que los comportamientos son vistos como apropiados o no en función de las normas sociales que rigen. Los sistemas simbólicos que los individuos utilizan para otorgar la valoración a las emociones, son sistemas que ya estaban allí, profundamente arraigados en el lenguaje, las tradiciones e historia, por esto, su significado es público y compartido (Bruner, 2006). El grupo social, la comunidad o el país en que se vive, provee a las personas de tradiciones, instituciones y costumbres convencionalizadas, relativamente permanentes que desempeñan una función importante en el desarrollo de intereses, afectos, objetos o circunstancias que a menudo se encuentran en la base de la formación de las imágenes y la provisión de material para los procesos constructivos de la emoción. En otras palabras, el entorno social modela no solo la expresión de las emociones sino la misma experiencia emocional.

La cultura emocional se hace presente en las valoraciones otorgadas a la expresión de ciertas emociones, así como en el manejo para prevenir o advertir sobre aquellas emociones que deben ser controladas, reguladas, incluso reprimidas. En la cultura mexicana se resalta la importancia de las relaciones interpersonales; los papeles sociales que desempeñan sus miembros, así como su pertenencia grupal para la constitución de la identidad personal (Sánchez-Aragón y Díaz-Loving, 2009). Los mexicanos valoran a la familia o al grupo de pertenencia sobre la persona, al igual que emociones como la vergüenza, la devoción y la simpatía; mientras las emociones de enojo, agresión, desprecio, determinación, envidia, odio, dolor y orgullo son indeseables (Díaz-Guerrero, 2003). De igual forma, se ha reconocido que las emociones colectivas que prevalecen en los mexicanos, aquellas con las que crean, conservan y transforman los conflictos que permean las interacciones sociales y que influyen en la acción colectiva son de tendencia negativa, pues sobresalen las emociones de miedo, enojo y tristeza (Rodríguez-Hernández et al., 2019).

La mayor parte de la experiencia emocional en los mexicanos es externa e interactiva, favoreciendo la expresividad y las formas de compartir y ser afectuoso, aunque evitando revelar emociones que socialmente puedan ser indeseables o inadecuadas (Páez et al., 2000). En este marco, el meme resulta ser una herramienta comunicacional de alto impacto para expresar y experimentar las emociones inapropiadas en la cultura mexicana, mediante la sátira y el humor. Los memes permiten representar el mundo interno, ilustrar procesos íntimos y brindar diferentes miradas a las vivencias personales -lo cual es indeseable socialmente-dando paso a comunidades de sentido, en torno de las cuales, se construyen referentes que operan como unidades culturales que permiten la articulación de un conjunto particular de actos comunicativos que proveen de sentidos identitarios, así como nuevas posibilidades de actuar y de entender las emociones propias y las de los otros.

\section{OBJETIVOS}

El objetivo de este trabajo es examinar la prevalencia de las emociones que se expresan y experimentan en un perfil de Facebook de universitarios sobre la pandemia 
Rodríguez-Hernández, G., Cruz Calderón, K. P., Ramírez Hernández, M. Expresión y experiencia emocional de la pandemia covid-19 mediante la memética en un perfil de Facebook de universitarios mexicanos

COVID-19. Se presume que los memes de la pandemia reflejan la cultura emocional mexicana; es decir: a) valoración de la familia o al grupo de pertenencia sobre la persona, b) las emociones de enojo, agresión, desprecio, determinación, envidia, odio, dolor y orgullo como indeseables, c) la vergüenza, la devoción y la simpatía como emociones deseables.

\section{METODOLOGÍA}

Para estudiar el sistema y ambiente de interactividad que favoreció el flujo de memes sobre la pandemia en un perfil de Facebook, se utilizó la técnica de etnografía virtual, la cual favoreció el estudio en la virtualidad (González y Hernández, 2008). El estudio de caso permitió realizar análisis cualitativo de contenido a cada uno de los memes recuperados.

El perfil de Facebook - entre las redes sociales, es la que más usuarios tienen en el mundo con más de 2 millones de usuarios. Gracias a su éxito y gran adhesión, es considerada como la red que influencia directamente en la política, la cultura y la opinión pública de los usuarios - en análisis es utilizado por universitarios para comunicar información relacionada con la vida académica y reporta 538 seguidores. Esta community online de mujeres y hombres nativos digitales, sugiere que conocen y utilizan los memes de Internet. La selección del perfil también se debió a la cercanía con la institución a la que pertenecen los usuarios, sin que se tuviera influencia alguna en la administración del perfil de Facebook en análisis.

La recuperación de los memes se realizó durante los meses de marzo a julio de 2020. Se capturaron memes $(\mathrm{N}=113)$ de imágenes verbo-visuales de naturaleza estática, cuya composición combina una imagen - fotografía o dibujo - sobre la que se inserta un texto, aunque de forma menos frecuente se identificaron memes exclusivamente textuales o visuales. De los cuales solo 55 (48.7\%) expresaban emociones vinculadas a la pandemia. Durante el proceso de análisis se utilizó un procedimiento de autocontrol muy estricto para garantizar que la calidad de la investigación científica se cumpliera en la medida de nuestros conocimientos y se ajustara a las normas de las buenas prácticas científicas (De la Cuesta, 2015). Se construyó una lista de cotejo con las características otorgadas a cada emoción. El análisis se realizó en dos momentos. En el primero, cada uno de los autores de este artículo, examinó los memes de forma individual. En el segundo momento, los memes se analizaron en trabajo grupal. Las imágenes bajo análisis se pueden reproducir sin necesidad de atribución al estar libres de copyright.

\section{RESULTADOS}

Tras examinar el corpus de datos reunido, se advirtieron una serie de características generales. En relación a la imagen, los recursos iconográficos empleados fueron referentes niños y niñas; animales comunes -gatos y perros-; famosos -políticos, deportistas, actores, etc.-; incluso personajes de ficción y material fotográfico, el cual se utilizó para difundir eventos socio-políticos relacionados con la pandemia. La

Vivat Academia. Revista de Comunicación. 2021, n 154, 89-106 
Rodríguez-Hernández, G., Cruz Calderón, K. P., Ramírez Hernández, M. Expresión y experiencia emocional de la pandemia covid-19 mediante la memética en un perfil de Facebook de universitarios mexicanos

mayoría de los memes utilizan la tipografía 'Impact', en color blanco con predominio de la mayúscula (ver Tabla 1).

Tabla 1. Emociones representadas en los memes

\begin{tabular}{|c|c|c|c|}
\hline Emoción & Frecuencia & Porcentaje & Referentes \\
\hline \multirow{4}{*}{ Pesimismo } & \multirow{4}{*}{13} & \multirow{4}{*}{11.5} & Personaje de ficción \\
\hline & & & Jesús hijo de Dios \\
\hline & & & Personas comunes \\
\hline & & & Actores \\
\hline \multirow{4}{*}{ Desesperación } & \multirow{4}{*}{10} & \multirow{4}{*}{8.8} & Actores \\
\hline & & & Personaje de ficción \\
\hline & & & Personaje histórico \\
\hline & & & Animales \\
\hline \multirow{4}{*}{ Miedo } & \multirow{4}{*}{7} & \multirow{4}{*}{6.2} & Personaje de ficción \\
\hline & & & Texto \\
\hline & & & Persona común \\
\hline & & & Personaje de ficción \\
\hline \multirow{2}{*}{ Soledad } & \multirow{2}{*}{6} & \multirow{2}{*}{5.3} & Animales \\
\hline & & & Personaje de ficción \\
\hline \multirow{2}{*}{ Asombro } & \multirow{2}{*}{5} & \multirow{2}{*}{4.4} & Personaje de ficción \\
\hline & & & Persona común \\
\hline Optimismo & 3 & 2.7 & Personajes de ficción \\
\hline Serenidad & 3 & 2.7 & Texto \\
\hline Alegría & 2 & 1.8 & Famosos \\
\hline \multirow{3}{*}{ Enojo } & \multirow{3}{*}{2} & \multirow{3}{*}{1.8} & Personaje de ficción \\
\hline & & & Personaje de ficción \\
\hline & & & Jesús hijo de Dios \\
\hline Orgullo & 2 & 1.8 & Personajes políticos \\
\hline Tristeza & 2 & 1.8 & Personaje de ficción \\
\hline Total & 55 & 48.7 & \\
\hline
\end{tabular}

Fuente: Elaboración propia

Pese a la diversidad, se advierte la preeminencia de algunas emociones. La primera de ellas, el pesimismo. Estado de ánimo con tendencia a percibir el aspecto más negativo o más desfavorable de la emergencia sanitaria. Para la expresión de esta emoción se hace uso de casi todos los referentes con excepción de imágenes de niños y textuales (Figura 1). 
Rodríguez-Hernández, G., Cruz Calderón, K. P., Ramírez Hernández, M. Expresión y experiencia emocional de la pandemia covid-19 mediante la memética en un perfil de Facebook de universitarios mexicanos

\section{NO SEAN GACHOS DEN MAS OPCIONES $\odot \odot \Theta$}

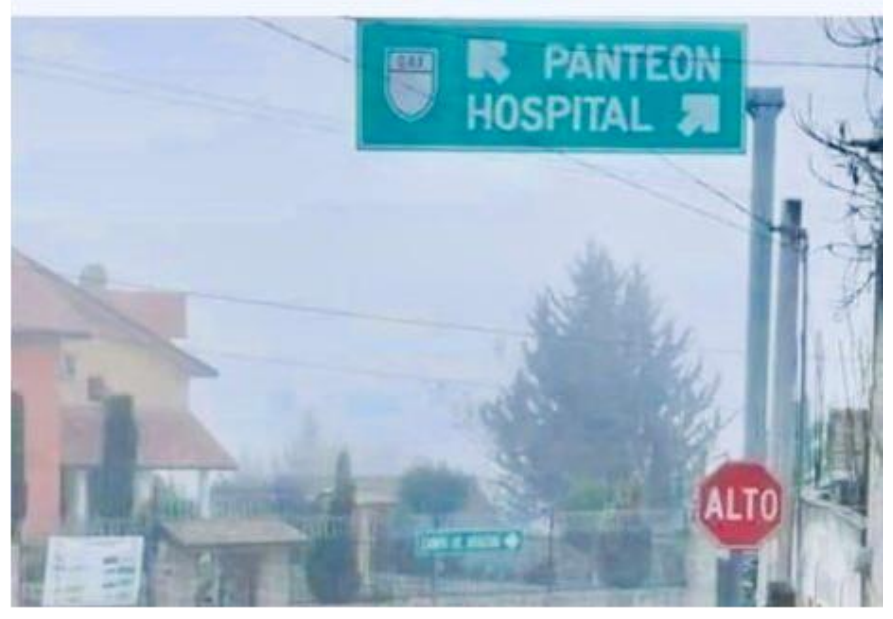

Figura 1. Ejemplo de Pesimismo

La desesperación, fue la segunda emoción más prevaleciente, y hace referencia a la pérdida de la paciencia o de la tranquilidad de ánimo. Se representa al COVID-19 como un mal irreparable (Figura 2).

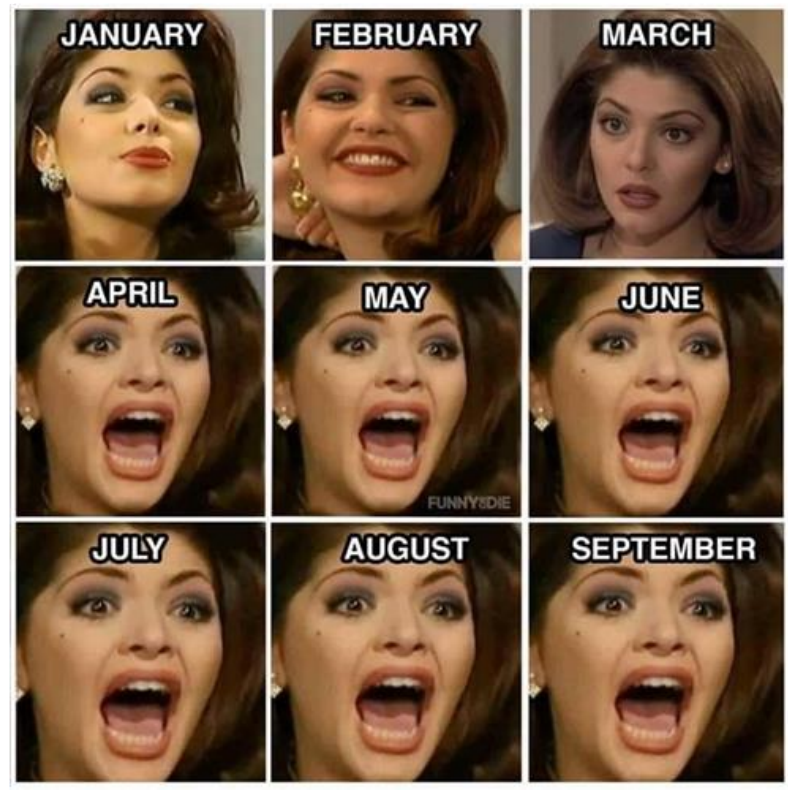

Figura 2. Ejemplo de Desesperación

Otra de las emociones más recurrente, fue el miedo. Emoción asociada a la amenaza grave, física o psicológica (Fredickson, 2003). Es un sentimiento desagradable que expresa contrariedad (Figura 3). 
Rodríguez-Hernández, G., Cruz Calderón, K. P., Ramírez Hernández, M. Expresión y experiencia emocional de la pandemia covid-19 mediante la memética en un perfil de Facebook de universitarios mexicanos

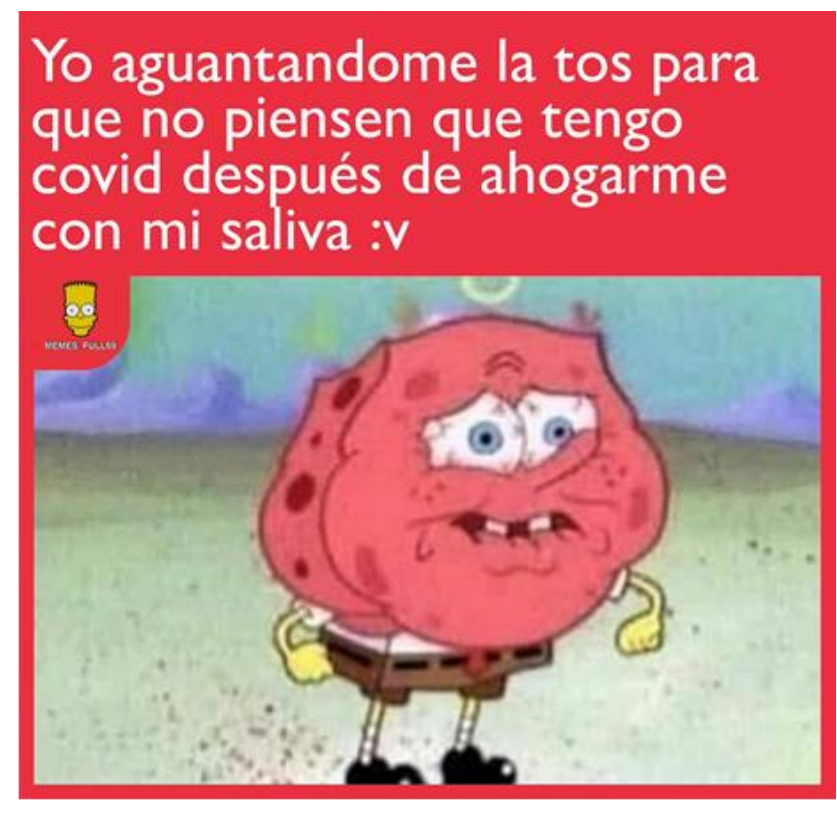

Figura 3. Ejemplo de Miedo

El aislamiento social que decreto la pandemia, hizo evidente la emoción de soledad. Esta emoción se asocia con la falta de contacto humano; sin embargo, también se caracteriza por la falta de un acompañamiento que genera el sentimiento de soledad (Figura 4).

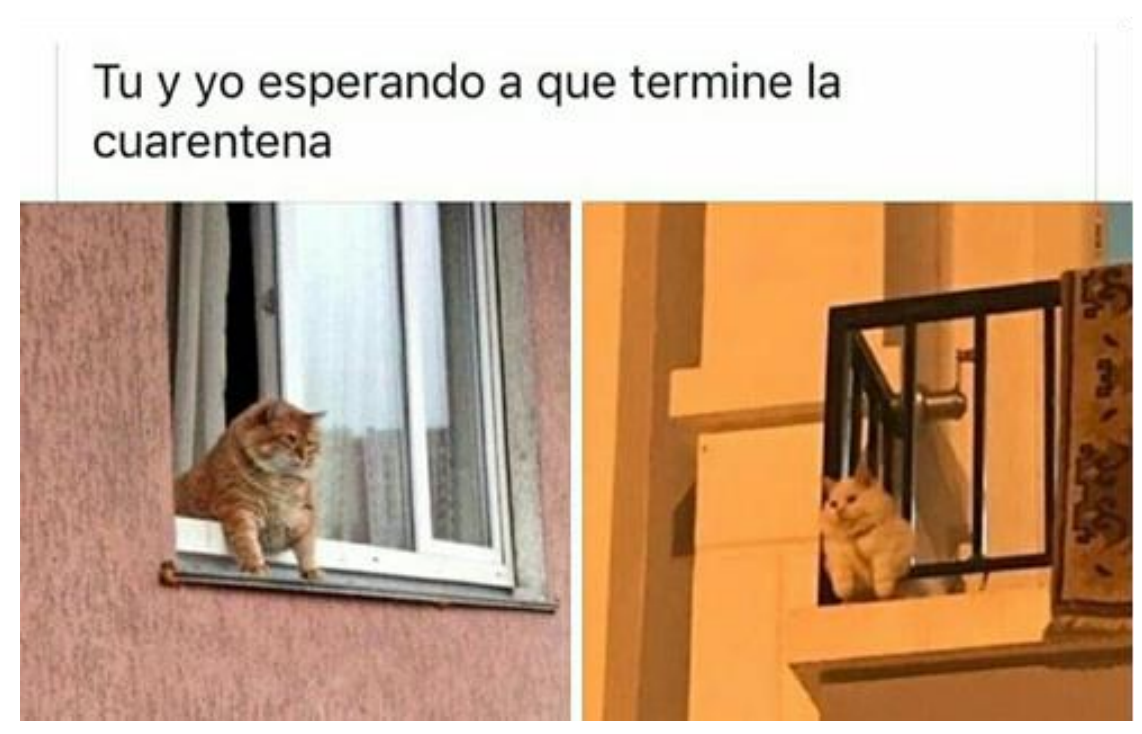

Figura 4. Ejemplo de Soledad

También, se advirtieron emociones positivas como el optimismo, el cual se relaciona con la confianza que las personas tienen acerca del futuro con expectativas positivas generales hacia la vida. Entre las condiciones adversas que generó la pandemia, se vislumbran algunos aspectos que pueden recuperarse para beneficio ante la crisis sanitaria en puerta (Figura 5). 
Rodríguez-Hernández, G., Cruz Calderón, K. P., Ramírez Hernández, M. Expresión y experiencia emocional de la pandemia covid-19 mediante la memética en un perfil de Facebook de universitarios mexicanos



Figura 5. Ejemplo de Optimismo

Otra emoción de este tipo fue la serenidad, sentimiento positivo, causado por la conciencia de tener controlados los pensamientos y sentimientos desagradables y por saber gozar de momentos y sensaciones desagradables (Fredickson, 2003).

En las emociones representadas en los memes bajo análisis, se aprecia que estas, no son emociones básicas de alta activación (Hansberg, 2001; Ekman et al., 1982; Plutchnick, 1980); por el contrario, emociones como el pesimismo, la soledad, el optimismo y la serenidad son emociones de baja activación que se caracterizan por la controlabilidad situacional. Proceso cognitivo básico que refiere una atribución o interpretación a una situación que genera conflicto por la incertidumbre sobre el control que se pueda tener sobre la misma (Cano y Zea, 2011). La sensación de control suele producir tranquilidad, incluso, orgullo. El control implica autoconfianza, convencimiento de que se puede afrontar la situación con recursos propios.

Se aprecia que la pandemia, por sí misma, no fue la generadora del conflicto, sino las distintas interpretaciones que de esta fluían, la falta de información o la imposibilidad de comprender todos los elementos que la configuran, fue lo que posiblemente, propicio que los universitarios usuarios del perfil de Facebook en análisis, hicieran uso de la memética para dar respuesta a la dificultad subyacente y la contingencia a la que hacían frente. Los memes representan respuestas congruentes, mediante referentes sencillos y positivos o perjudiciales y peligrosos que permitieron edificar pautas expresivas para valorar y planificar la nueva realidad que trajo la pandemia. 
Rodríguez-Hernández, G., Cruz Calderón, K. P., Ramírez Hernández, M. Expresión y experiencia emocional de la pandemia covid-19 mediante la memética en un perfil de Facebook de universitarios mexicanos

\section{DISCUSIÓN}

Tras la experiencia metodológica en el uso de la etnografía virtual para el análisis de los memes como patrón de información para expresar y experimentar emociones de la pandemia COVID-19 en una community online, se pudo observar de primera mano la interacción y la comunicación entre universitarios usuarios de un perfil de Facebook. Amén de que los resultados obtenidos aportan al conocimiento teórico sobre la expresión y experiencia emocional en comunidades virtuales, a más de que los resultados alcanzados podrán generalizarse a otros que presenten condiciones teóricas y metodológicas similares (González y Hernández, 2008).

Tal y como se planteó al inicio de esta investigación, la experiencia emocional en los mexicanos al ser preferentemente externa e interactiva (Páez et al., 2000) favoreció la expresividad y las formas de compartir y ser afectuoso durante la pandemia, a través de la memética. Se evidencio que la comunidad bajo análisis se comunicó aun estando diseminados geográficamente y en aislamiento social. Expresaron y experimentaron emociones mediante el uso de memes, proceso comunicativo que les permitió dar sentido a la pandemia y al encierro social que llegó con está (Almeida, 2019; Pérez et al., 2014). También, se reconoció al meme como un sistema complejo en el que interviene procesos cognitivos y juegos de lenguaje propios de la cultura donde se usan (Milber, 2016). El elemento original imitado tiene un carácter multisemiótico, toda vez que se recuperaron memes con una frase o secuencia de frases, una imagen, o una combinación de estos (Pérez, 2017; Ruiz 2018).

A la luz del objetivo de este trabajo, el cual fue examinar la prevalencia de las emociones que se expresan y experimentan en un perfil de Facebook de universitarios sobre la pandemia COVID-19, se comprueba que en esta comunidad virtual prevalece la expresión de emociones negativas - pesimismo, desesperación, miedo y soledad , aunque también se expresan emociones positivas como el asombro, el optimismo y la serenidad. Lo que lleva a comprobar parcialmente el supuesto de investigación planteado, pues si bien, prevalecieron emociones negativas, no son las que se han identificado como premisas histórico-socio-culturales de la expresión emocional en los mexicanos (Díaz-Guerrero, 2003; Rodríguez-Hernández et al., 2019; Sánchez-Aragón y Díaz-Loving, 2009) con excepción del miedo, el cual, expresa dominio de la situación que incluye enfrentarlo y vencerlo, supone una fortaleza para la búsqueda de apoyo mediante la comunicación. Aunque con menor frecuencia, el enojo también estuvo presente, y se expresa con mal humor o discusión con otros, además del control que implica alcanzar la calma (Díaz-Guerrero, 2003).

Junto con las emociones arriba mencionadas, también se registraron las emociones de pesimismo, desesperación y soledad, las cuales colocan a la incertidumbre en el núcleo cognitivo-emocional en el que se ancló la pandemia. Estas emociones negativas crecieron al amparo de las dudas que invadieron todos los aspectos esenciales de la vida (salud, trabajo, familia, economía, proyectos de vida, etc). La incertidumbre proviene del largo tiempo transcurrido desde que comenzó la cuarentena obligatoria, hasta la demora de todos los planes y proyectos que la persona necesita y está 
Rodríguez-Hernández, G., Cruz Calderón, K. P., Ramírez Hernández, M. Expresión y experiencia emocional de la pandemia covid-19 mediante la memética en un perfil de Facebook de universitarios mexicanos

acostumbrada a realizar. Ante el presente y el futuro incierto, la mente trabaja llenando los agujeros negros de información y certeza con ideas, presentimientos, creencias negativas y catastróficas, alimentando así la desesperación y el pesimismo ante el provenir.

De la misma manera, se identificaron emociones como el asombro, el optimismo y la serenidad, emociones consideradas positivas, toda vez que provocan cambios en la actividad cognitiva, que a la larga pueden producir cambios conductuales. Amplían las tendencias de pensamiento y acción, así como la construcción de recursos personales para afrontar situaciones difíciles o problemáticas que produce la transformación de la persona, la cual resulta creativa, con un conocimiento más profundo de las situaciones (Fredrickson, 2003).

La identificación de emociones positivas que influyen en el correcto funcionamiento biológico, así como de emociones negativas que paralizan el desarrollo personal y la vida diaria, y fungen como señal para reevaluar la situación e impulsar cambios mediante estrategias psicológicas para manejar las emociones y los estados emocionales. Sin duda, obliga a ampliar el espectro de comprensión de la expresión y experiencia emocional que se sucedieron durante la pandemia, al menos para communities online de nativos digitales. Si bien, las emociones identificadas, no tienen una sola dirección - positivas o negativas - sí muestran una gama de matices, los cuales, a simple vista parecieran opuestos, pero que bajo análisis se reflejan complementarios, necesarios para entender y hacer frente a la nueva realidad que se presentó intempestiva y abrumadora, ante la cual la cognición y la emoción van de avanzada. En este contexto los memes cumplieron su función en el acto comunicativo (Pérez et al., 2014) para expresar emociones y explicar lo que acontecía mediante polifonías narrativas que sobrevinieron en el flujo de la vida cotidiana (EnríquezRosas, 2016).

Es muy importante resaltar que las emociones como el pesimismo, la soledad, el optimismo y la serenidad son emociones de baja activación que se caracterizan por la controlabilidad situacional (Cano y Zea, 2011), lo cual refiere a una descripción de la situación realizada a través del meme con imágenes sencillas y positivas o negativas que permitieron construir patrones descriptivos con valoraciones, planificaciones y retrospecciones que ayudaron a los participantes en estudio, establecer metas, creencias, comportamientos y emociones entorno a la crisis sanitaria, social, económica, personal, laboral, etc., por la que se transcurre en tiempo del coronavirus.

Los resultados dirigen a no corroborar el supuesto de investigación sobre la valoración de la familia o al grupo de pertenencia sobre la persona, toda vez que los referentes utilizados en la construcción de los memes, preferentemente son fotos de objetos inanimados, y personajes de ficción en lo individual, lo cual podría deberse a que los mexicanos valoran a la familia o al grupo de pertenencia sobre la persona (Díaz-Guerrero, 2003), por lo que no son referentes que deban utilizarse de forma 
Rodríguez-Hernández, G., Cruz Calderón, K. P., Ramírez Hernández, M. Expresión y experiencia emocional de la pandemia covid-19 mediante la memética en un perfil de Facebook de universitarios mexicanos

mordaz. Se constata la función del meme de transmitir información cultural de forma longitudinal y horizontal ((Dawkins, 1993, Milner, 2016; Ruiz, 2018).

\section{CONCLUSION}

Un evento tan disruptivo como la pandemia del nuevo coronavirus Sars-Cov-2, generó y generará diversos efectos en la salud de la población mundial, más aún si no existen vacunas ni tratamientos efectivos a corto o mediano plazo, pues la incertidumbre de la duración de las medidas de distanciamiento social, además del alto impacto económico, social y sanitario estimado, lleva a potenciar la necesidad de mantenerse conectado por internet y utilizar las herramientas a su alcance para comunicarse. En este contexto, la memética irrumpió en el mundo simbólico para comunicar no solo emociones y estados de ánimo, también pensamientos y expectativas sobre la nueva realidad en relaciones inter e intra subjetivas.

Los hallazgos de este estudio, obligan a reflexionar sobre las emociones negativas, las cuales han sido el foco de atención de la investigación y tratamiento en psicología bajo el argumento que estas alteran la salud mental y propician la enfermedad (Selligman, 2014). Sin embargo, en los últimos tiempos, la ciencia psicológica ha reconocido que tanto las emociones positivas como las negativas son procesos que se activan cada vez que el aparato psíquico detecta algún cambio significativo para la persona, lo que las convierte en un proceso altamente adaptativo al tener la propiedad de dar prioridad a la información relevante para cada quien. Proceso en el cual, la mimética cumplió la función de configurar sentido, en torno a las emociones que la pandemia provoco. Los memes se constituyeron en referentes que operaron como unidades culturales que articularon actos comunicativos para proveer sentido de identidad a los usuarios (Arango, 2015; Pérez et al., 2014). En particular, a los usuarios del perfil de Facebook en estudio, los cuales se identificaron pesimistas, desesperados, solos y con miedo ante la pandemia, pero con optimismo hacia el futuro. Lo que implicó un sistema de procesamiento de información altamente jerarquizado donde los memes proporcionaron los recursos y el tiempo adecuado de respuesta para hacer frente a la crisis emocional que generó la pandemia en una generación donde lo gráfico y lo inmediato se sobrevalora.

El reconocimiento, experiencia y expresión de emociones no solo es para que las personas se sientan bien en el momento, pues las emociones positivas al igual que las negativas cumplen una función adaptativa con la intención de alcanzar el bienestar a largo plazo y con ello, porque no, la felicidad.

\section{REFERENCIAS}

Aguado, L. (2005). Emoción, afecto y motivación. Alianza Editorial.

Almeida, J. (2019). Reflexión sobre el impacto de los memes en el léxico coloquial de estudiantes universitarios. https://bit.ly/3cGr9TO

Vivat Academia. Revista de Comunicación. 2021, n 154, 89-106 
Rodríguez-Hernández, G., Cruz Calderón, K. P., Ramírez Hernández, M. Expresión y experiencia emocional de la pandemia covid-19 mediante la memética en un perfil de Facebook de universitarios mexicanos

Arango, L. (2015). Una aproximación al fenómeno de los memes en Internet: claves para su comprensión y su posible integración pedagógica. Comun. Mídia consumo, São Paulo, 12(33), 110-132. https:// bit.ly/2S5jdBJ

Ballesteros, E. (2016). Circulación de memes en WhatsApp: ambivalencias del humor desde la perspectiva de género. EMPIRIA. Revista de Metodología en Ciencias Sociales, 35, 21-41. https://doi.org/10.5944/empiria.35.2016.17167

Bruner, J. (2006). Actos de significado. Más allá de la revolución cognitiva. Alianza Editorial.

Calhoun, C. \& Solomon, R. (1996). ¿Qué es una emoción? Lecturas clásicas de psicología filosófica. Fondo de Cultura Económica.

Cano, M. y Zea, J. (2012). Manejar las emociones, factor importante en el mejoramiento de la calidad de vida. Revista Logos Ciencia E Tecnología, 4(1), 58-67.

Dawkins, R. (1993). El gen egoísta. Las bases biológicas de nuestra conducta. Salvat.

De la Cuesta, B. C. (2015). La calidad de la investigación cualitativa: de evaluar a lograrla. Texto y Contexto Enfermagem, 24(3), 883-90. https://doi.org/10.1590/0104$\underline{070720150001150015}$

Díaz-Guerrero, R. (2003). Bajo las garras de la cultura. Psicología del Mexicano 2. Trillas.

Ekman, P., Friesen, W. \& Ellsworth, P. (1982). What emotion categories or dimensions can observers judge from facial behavior? En P. Ekman (Ed.), Emotion in the human face. (pp. 39-55). Cambridge University Press.

Enriquez-Rosas, R. (2016). Emociones sociales y transdisciplina: reflexiones sobre una perspectiva teórica para el abordaje de problemas contemporáneos en el campo del bienestar emocional y social. En T., Zohn-Muldoon, E., Gómez-Gómez y R., Enríquez-Rosas (Coords.). Psicoterapia y problemas actuales. Debates y alternativas. ITESO.

Fredrickson, B. (2003). The Value of Positive Emotions. American Psychologist, 91, 330335. https:// doi.org/10.1511/2003.4.330

Gallardo, E. (2012). Hablemos de estudiantes digitales y no de nativos digitales. Ciències de l'Educación, junio, 7-21.

Garrido, I. (2000). Psicología de la emoción. Síntesis.

González, M. y Hernández, M. J. (2008). Interpretación de la virtualidad. El conocimiento mediado por espacios de interacción social. Apertura, 8 (9), 8-20. 
Rodríguez-Hernández, G., Cruz Calderón, K. P., Ramírez Hernández, M.

Expresión y experiencia emocional de la pandemia covid-19 mediante la memética en un perfil de Facebook de universitarios mexicanos

Gordon, S. (1990). Social Structural effects on emotion. En T., Kemper (Ed.), Research Agenda in the Sociology of Emotion. State University of New York Press.

Hansberg, O. (2001). La diversidad de las emociones. Fondo de Cultura Económica.

Izquierdo, M. y Barbeta, M. (2013). La transcendencia de lo cotidiano: vínculos, chistes y subjetividad. Politica y sociedad, 50(3), 1097-1131. https://doi.org/10.5209/rev_poso.2013.v50.n3.41556

Johnson, M., Saletti-Cuesta, L. y Tumas, N. (2020). Emociones, preocupaciones y reflexiones frente a la pandemia del COVID-19 en Argentina. Ciencia \& Saude Colectiva, 25, 2447-2456. https:// doi.org/10.1590/1413-81232020256.1.10472020

Lyubomirsky, S., King, L. \& Diener, E. (2005). The Benefits of Frequent Positive Affect: Does Happiness Lead to Success?. Psychological Bulletin, 131(6), 803-855. https:// doi.org/10.1037/0033-2909.131.6.803

Mercadillo, R., Díaz, J. y Barrios, F. (2007). Neurobiología de las emociones morales. Salud Mental, 30 (3), 1-11. https:// bit.ly/3jisO4s

Milner, R. (2016). The World Made Meme: Discourse and Identity in Participatory Media Culture, dissertation, University of Kansas. https://doi.org/10.7551/mitpress/9780262034999.001.0001

Observatorio Nacional Ciudadano (2020). https:/ / onc.org.mx/covid19

Páez, D., Fernández, I. y Mayordomo, S. (2000). Alexitimia y cultura. En D., Páez \& M., Casullo (Comps.), Cultura y Alexitimia: ¿Cómo expresamos aquello que sentimos? Paidós

Pérez, G. (2017). Teoría del meme. En Pérez Salazar, G. El meme en Internet. Identidad y usos sociales (p. 15-68). Fontamara

Pérez, G., Aguilar, A. y Guillermo, M. (2014). El meme en internet. Usos sociales, reinterpretación y significados, a partir de Harlem Shake. Argumentos, 27 (75),79-100. https:// bit.ly/2S5NaBE

Plutchik, R. (1980). Emotion: A psychoevolutionary synthesis. Harper and Row. https://doi.org/10.2307/1422394

Rodríguez-Hernández, G., Domínguez-Zacarías, G. y Escoto, C. (2017). Evaluación psicométrica de la escala de felicidad de Lima en una muestra mexicana. Universitas Psychologica, 16(4), 1-10. https://doi.org/10.11144/Javeriana.upsy16-4.epef

Rodríguez-Hernández, G., Rodríguez, O. y Gómez, B. (2019). Clima emocional en una muestra de habitantes del Estado de México. En R., Enríquez \& O., Sánchez 
Rodríguez-Hernández, G., Cruz Calderón, K. P., Ramírez Hernández, M.

Expresión y experiencia emocional de la pandemia covid-19 mediante la memética en un perfil de Facebook de universitarios mexicanos

(Coords), Las emociones en los procesos pedagógicos y artísticos. México: ITESO, UNAM. https://doi.org/10.2307/j.ctv11vcd3k.4

Ruiz, J. (2018) Una aproximación retórica a los memes de internet. Revista Signa, 27, 995-1021. https:// doi.org/10.5944/signa.vol27.2018.21856

Sánchez- Aragón, R. y Díaz-Loving, R. (2009). Reglas y preceptos culturales de la expresión emocional en México: su medición. Univesitas Psychologica, 8 (3), 793-805. https://bit.ly/3i8vxMp

Seligman, M. (2014). Florecer. La nueva psicología positiva y la búsqueda del bienestar. Océano.

Urroz, T. (2005). Cómo reírse de una misma y no morir en el intento. Dossiers Feministes, 8, 7-14. https://bit.ly/2Gf1Rjs

Vera, E. (2016). El meme como nexo entre el sistema educativo y el nativo digital: tres propuestas para la enseñanza de lenguaje y comunicación. Revista Educación y Tecnología, 5, 8 (2), 1-15. https:/ / bit.ly/3n03a6z

Vigara, A. (2013). El chiste, texto lúdico. En J. Aguirre (Editor), Humor y Comunicación. Homenaje a Ana María Vigara. Espectáculo Revista de Estudios Literarios 50, 8-27. https://bit.ly/36dLa2z

\section{AUTOR/ES:}

\section{Gabriela Rodríguez-Hernández:}

Master en Psicología Social por la Universidad Autónoma del Estado de México (UNAM) y Doctora en Ciencias Sociales por la Universidad Autónoma Metropolitana (UAM). Profesora Investigadora en la licenciatura en Psicología de la Universidad Autónoma del Estado de México. Autora de artículos científicos indexados y capítulos de libro en el área de psicología social, comunicación y emociones.

Orcid ID: https://orcid.org/0000-0003-2821-9672

Google Scholar: https://scholar.google.com/citations?user=a_mDnaIAAAAJ\&hl=es ResearchGate: https://www.researchgate.net/profile/Gabriela-Rodriguez-

Hernandez

\section{Karla Patricia Cruz Calderón:}

Profesora del Centro Universitario UAEM Ecatepec, Maestra en Ciencias de la Salud y Licenciada en Psicología por la Universidad Autónoma del Estado de México, tiene un Diplomado en Sustentabilidad Aplicada por el Centro de Especialistas en Gestión Ambiental, MIDE. Cuenta con ponencias en encuentros académicos y congresos internacionales de Psicología social, tiene publicaciones relacionadas con problemas sociales, identidad social, psicología política y clima emocional.

ORCID: https://orcid.org/0000-0003-1665-1820 
Rodríguez-Hernández, G., Cruz Calderón, K. P., Ramírez Hernández, M. Expresión y experiencia emocional de la pandemia covid-19 mediante la memética en un perfil de Facebook de universitarios mexicanos

Google Scholar: https:/ / scholar.google.com/citations?hl=es\&user=2c1h0FgAAAAJ

\section{Mariana Ramírez Hernández:}

Licenciada en Psicología por la Universidad Autónoma del Estado de México. 